http://jurnal.stmikroyal.ac.id/index.php/jurdimas

\title{
WORKSHOP MEMBANGUN SISTEM JARINGAN KOMPUTER BERBASIS PEER TO PEER DAN CLIENT SERVER DI SMK NEGERI 1 SETIA JANJI
}

\author{
Guntur Maha Putra ${ }^{*}$, Afdhal Syafnur ${ }^{1}$, Rolly Yesputra ${ }^{1}$ \\ ${ }^{1}$ Program Studi Sistem Informasi, STMIK Royal Kisaran, \\ Email : igoenputra@gmail.com
}

\begin{abstract}
SMK Negeri 1 Setia Janji is a vocational high school that is engaged in technology that has three departments namely RPL (Software Engineering), TSM (Motorcycle Engineering) and TKR (Light Vehicle Engineering). Department of RPL is focused into mastery of programming, for example in making dynamic web application, but after finished making web application needed a computer network so that application can be run and can be arranged through computer network system either peer to peer or client server, it needs to be done collaboration between mastery in the field of programming with mastery in the field of computer network systems, especially based on peer to peer and client server.
\end{abstract}

Keywords :Networking, peer to peer, client server

\begin{abstract}
Abstrak: SMK Negeri 1 Setia Janji adalah Sekolah Menengah Kejuruan yang bergerak di bidang teknologi yang memiliki tiga jurusan yaitu RPL (Rekayasa Perangkat Lunak), TSM (Teknik Sepeda Motor) dan TKR (Teknik Kendaraan Ringan). Jurusan RPL difokuskan ke dalam penguasaan pemrograman, misalnya dalam membuat aplikasi web dinamis, tetapi setelah selesai membuat aplikasi web tersebut maka diperlukan sarana jaringan komputer agar aplikasi tersebut dapat dijalankan dan dapat diatur melalui sistem jaringan komputer tersebut baik secara peer to peer maupun client server, oleh sebab itu perlu dilakukan kolaborasi antara penguasaan dibidang pemrograman dengan penguasaan di bidang sistem jaringan komputer khususnya berbasis peer to peer dan client server.
\end{abstract}

Kata kunci : Jaringan, peer to peer, client server

\section{PENDAHULUAN}

Dalam kehidupan masyarakat modern dewasa ini sadar maupun tidak sadar kita selalu menggunakan teknologi jaringan komputer sebagai sarana dalam mendukung aktifitas maupun tugas-tugas yang dilakukan.Dengan adanya jaringan komputer berbasis server transformasi data antar komputer bisa dikerjakan dengan mudah, cepat maupun terpusat, oleh karena itu efektifitas dan efisiensi bisa dicapai yang akhirnya produktifitas menjadi lebih tinggi dalam menyelesaikan berbagai jenis pekerjaan yang dilakukan. Menyahuti kebutuhan masyarakat akan kebutuhan perancangan teknologi jaringan komputer berbasis server baik dari segi sarana dan fasilitas, maka perlu adanya persiapan Sumber Daya Manusia (SDM) yang menguasai bidang tersebut.

SMK Negeri 1 Setia Janji adalah Sekolah Menengah Kejuruan yang bergerak di bidang teknologi yang memiliki tiga jurusan yaitu RPL (Rekayasa Perangkat Lunak), TSM (Teknik Sepeda Motor) dan TKR (Teknik Kendaraan Ringan). Jurusan RPL difokuskan ke dalam penguasaan 
http://jurnal.stmikroyal.ac.id/index.php/jurdimas

pemrograman misalnya dalam membuat aplikasi web dinamis, tetapi setelah selesai membuat aplikasi web tersebut maka diperlukan sarana jaringan komputer agar aplikasi tersebut dapat dijalankan dan dapat diatur melalui sistem jaringan komputer tersebut baik secara peer to peer maupun client server, oleh sebab itu perlu dilakukan kolaborasi antara penguasaan dibidang pemrograman dengan penguasaan di bidang sistem jaringan komputer khususnya berbasis peer to peer dan client server.

Khalayak sasaran pada pengabdian kepada masyarakat yang dilaksanakanadalah siswa/i SMK Negeri 1 Setia Janji kelas X-XII Jurusan RPL.

\section{METODE}

Metode pelaksanaan pengabdian kepada masyarakat ini adalah dengan cara melaksanakan kegiatan pelatihan dalam bentuk workshop, dengan melakukan pre-test, kegiatan inti berupa menjelaskan dasar teori pada modul dan praktek langsung kepada 23 orang siswa/I dan melakukan post-test. Berikut beberapa foto-foto dokumentasinya:

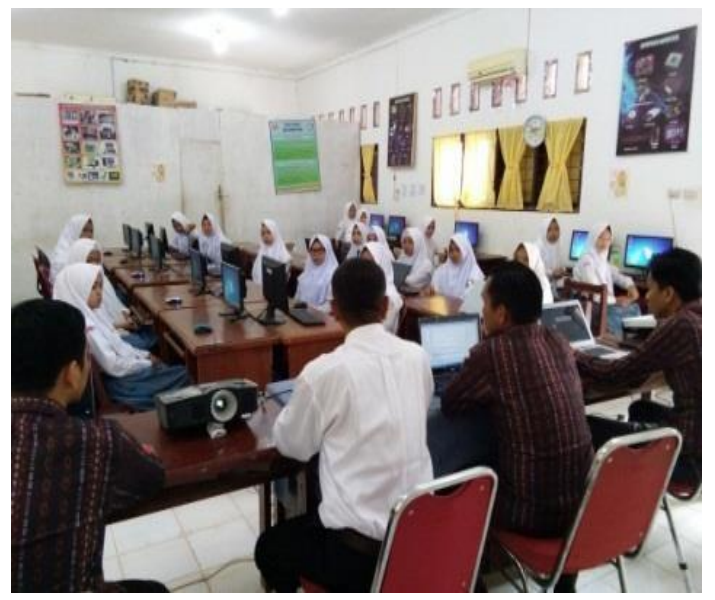

Gambar 1. Pengarahan Kepala Sekolah Sekaligus Pembukaan Acara Workshop

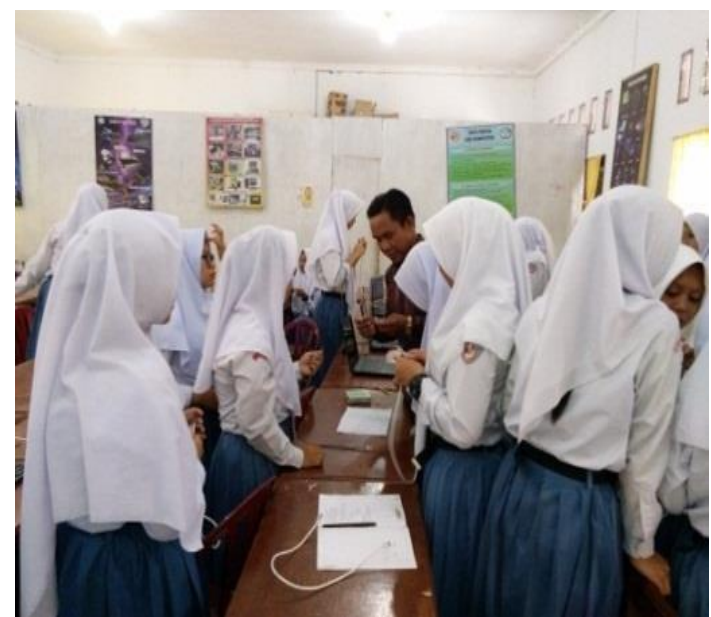

Gambar 2. Praktek Pemasangan Kabel Jaringan

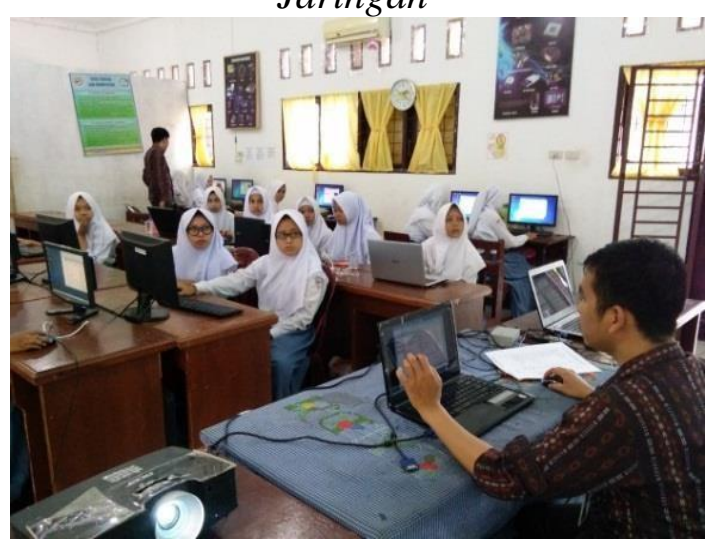

Gambar 3. Testing Koneksi Kabel Jaringan

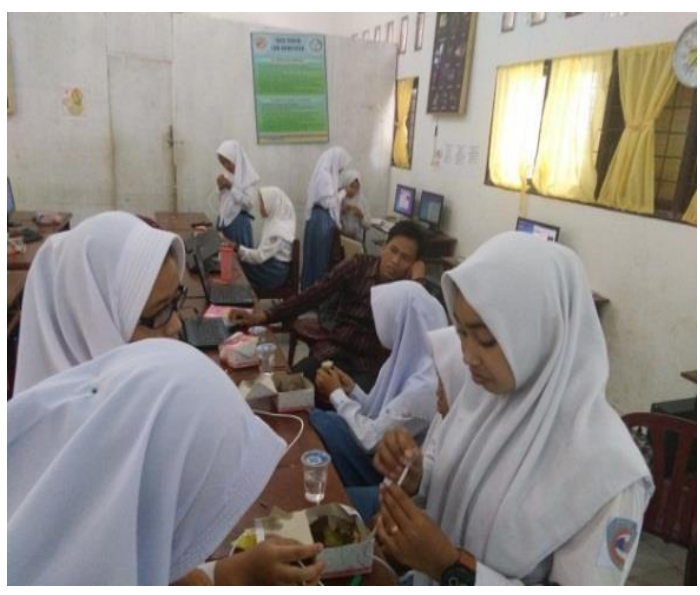

Gambar 4.Praktek Pemasangan Kabel Jaringan 
http://jurnal.stmikroyal.ac.id/index.php/jurdimas

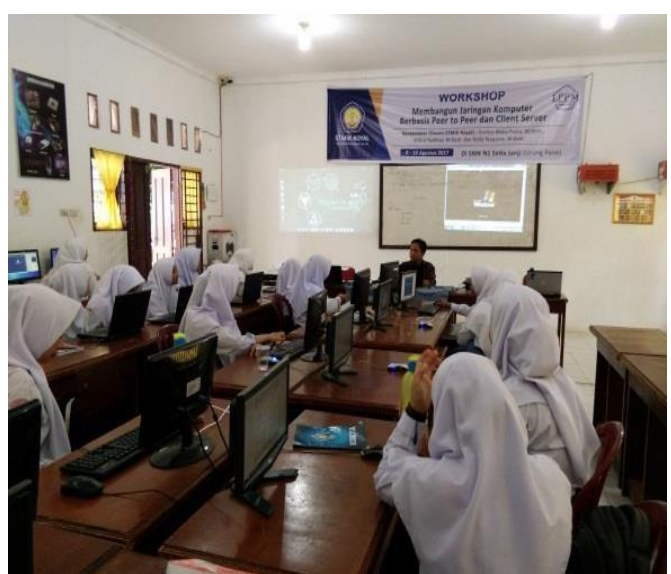

Gambar 5. Praktek Jaringan Berbasis Peer to Peer

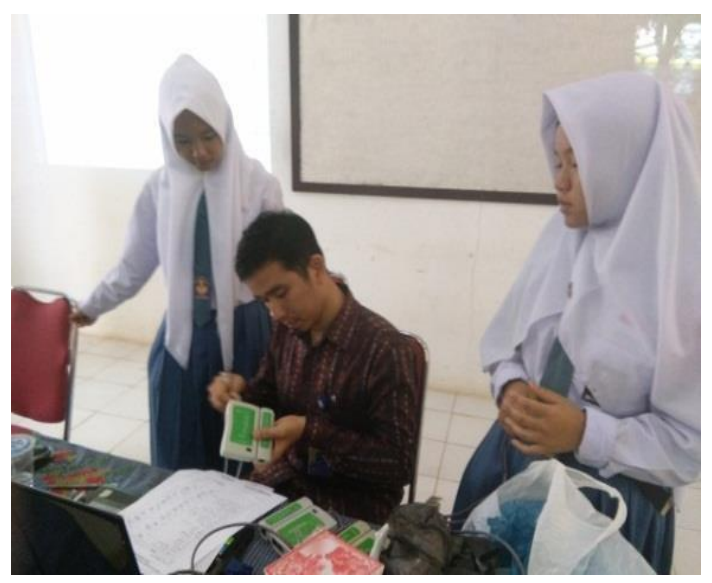

Gambar 6. Praktek Jaringan Berbasis Client Server

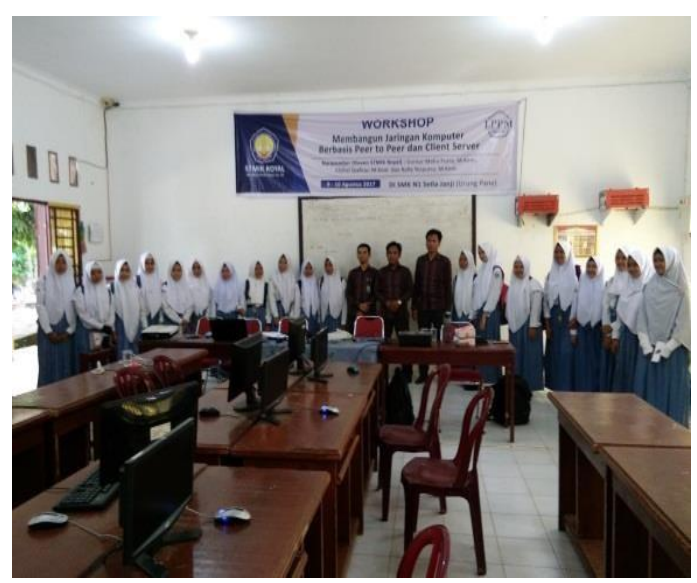

Gambar 7. Foto Narasumber Bersama Peserta Workshop

\section{PEMBAHASAN}

Peserta dari kegiatan pengabdian kepada masyarakat yang berbentuk workshop selama dua hari ini (9 s/d 10 Agustus 2017), adalah siswa/i dari SMK Negeri 1 Setia Janji dengan jurusan Rekayasa Perangkat Lunak (RPL) berjumlah 23 orang. Ketuntasan hasil workshop dapat dilihat dengan pengamatan maupun penilaian dari teori / praktikum yang dikerjakan. Keberhasilan dari kegiatan yang dilakukan diukur dengan rata-rata persentasi keseluruhan materi / praktek yang dilakukan siswa dengan target capaian $>=70 \%$.Untukmenghitung persentase ketuntasan siswa dalam kegiatan pengabdian ini, kami menggunakan rumus berikut:

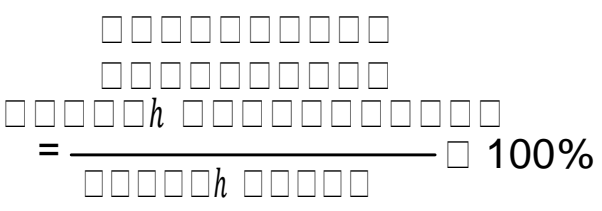

Berikut adalah hasil persentase ketuntasan siswa/I dari kegiatan pengabdian kepada masyarakat yang dilaksanakan, diuraikan dalam bentuk tabel berikut:

Tabel 1. Persentase Materi dan Praktek

\begin{tabular}{|c|c|c|c|}
\hline $\begin{array}{c}\text { Ha } \\
\text { ri }\end{array}$ & $\begin{array}{c}\text { Materi \& } \\
\text { Praktek }\end{array}$ & $\begin{array}{l}\text { Tunt } \\
\text { as } \\
\text { (oran } \\
\text { g) }\end{array}$ & $\begin{array}{c}\text { Perse } \\
\text { ntse } \\
(\%)\end{array}$ \\
\hline \multirow{3}{*}{1} & $\begin{array}{l}\text { 1. Pengkabelan } \\
\text { (straight \& } \\
\text { crossover) } \\
\end{array}$ & 21 & $91 \%$ \\
\hline & $\begin{array}{l}\text { 2. Konsep } \\
\text { Protocol } \\
\text { TCP/IP } \\
\end{array}$ & 15 & $65 \%$ \\
\hline & $\begin{array}{l}\text { 3. Instalasi OS } \\
\text { Client dan OS } \\
\text { Server } \\
\end{array}$ & 23 & $\begin{array}{c}100 \\
\%\end{array}$ \\
\hline 2 & $\begin{array}{l}\text { b. Praktek } \\
\text { Jaringan } \\
\text { Berbasis Peer }\end{array}$ & 18 & $78 \%$ \\
\hline
\end{tabular}


http://jurnal.stmikroyal.ac.id/index.php/jurdimas

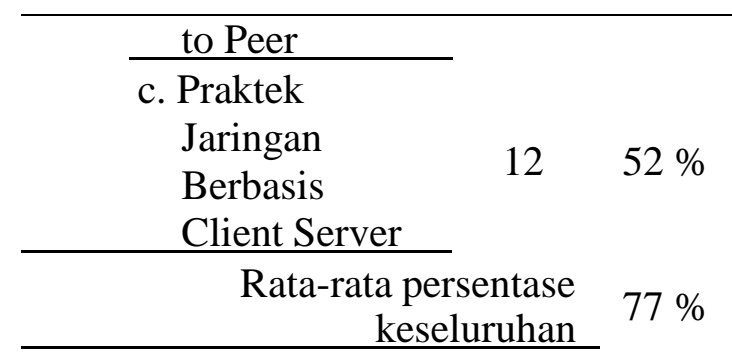

Gambar 8. Grafik Persentase Materi dan Praktek

Dari 23 orang siswa/i yang mengikuti kegiatan pengabdian, jika dirata-ratakan persentase ketuntasan mencapai rata-rata $77 \%$. Hal ini berarti secara rata-rata kegiatan pengabdian kepada masyarakat telah berhasil dilakukan dengan baik karena telah melampaui dari target capaian yaitu >= $70 \%$.

\section{SIMPULAN}

Kesimpulan dari kegiatan pengabdian kepada masyarakat ini adalah sebagai berikut :

1. Antusias siswa/i dalam mengikuti kegiatan pengabdian yang dilakukan sangat tinggi ditunjukkan dengan prosentasi kehadiran $100 \%$ dan kegiatan pengabdian kepada masyarakat telah berhasil dilakukan dengan baik dengan capaian rata-rata persentase ketuntasan mencapai $77 \%$ melampaui dari target capaian yaitu $>=$ $70 \%$.

2. Dengan adanya privileges berbasis active directory, memudahkan pekerjaan administrator dalam memanajemen organization unit, group dan user, pemberian hak akses (privileges) setiap user dan group, tidak harus melakukan setting satu per satu pada komputer client.

3. Respon kepala sekolah dan siswa-siswi sangat antusias, yang tercermin dengan adanya komunikasi timbal balik dengan para siswa sampai dengan akhir kegiatan workshop.

1. Tidak semuanya siswa memiliki pola pemikiran yang cepat tanggap dalam belajar, terutama pemahaman tentang jaringan komputer, mungkin dikarenakan adanya banyak faktor. Sehingga dibutuhkan teknik dari instruktur untuk menciptakan suasana komunikasi yang sederhana dengan menggunakan redaksi bahasa yang mudah dimengerti dan dipahami.

\section{DAFTAR PUSTAKA}

Madcoms. "Membangun Sistem Jaringan Komputer", Yogyakarta, Andi Publisher.

Melwin Syafizal, (2005). "Pengantar Jaringan Komputer", Yogyakarta, Andi Offset.

Winarno Sugeng, Theta Dinnarwaty Putri, (2015). "Jaringan Komputer Dengan TCP/IP”, Bandung, Modula.

I Putu Agus Eka Pratama, (2014). "Handbook Jaringan Komputer", Bandung, Informatika Bandung. 